\title{
Maternal Predictors for Quality of Life during the Postpartum in Brazilian Mothers
}

\author{
Mirna Fontenele de Oliveira1, Leslie Parker1, Hyochol Ahn'1, Hellen Lívia Oliveira Catunda², \\ Elizian Braga Rodrigues Bernardo², Mara Fontenele de Oliveira², Samila Gomes Ribeiro², \\ Cinthia Gondim Pereira Calou ${ }^{2}$, Franz Janco Antezana ${ }^{2}$, Paulo César Almeida², \\ Régia Christina Moura Barbosa Castro², Priscila de Souza Aquino², \\ Ana Karina Bezerra Pinheiro² \\ ${ }^{1}$ College of Nursing, University of Florida, Gainesville, USA \\ ${ }^{2}$ Department of Nursing, Federal University of Ceará, Fortaleza, Brazil \\ Email: mirnafontenele@ig.com.br
}

Received 20 February 2015; accepted 15 March 2015; published 18 March 2015

Copyright (C) 2015 by authors and Scientific Research Publishing Inc.

This work is licensed under the Creative Commons Attribution International License (CC BY). http://creativecommons.org/licenses/by/4.0/

(c) (i) Open Access

\begin{abstract}
Introduction: The postpartum period can have a significant physical, emotional, and social impact on the quality of a woman's life. Most postpartum research has focused on physical complications and only a few studies have specifically investigated quality of life. The purpose of this study was to explore predictors affecting the quality of life of postpartum Brazilian mothers. Study Design and Methods: A cross-sectional Quality of Life survey was performed in 210 Brazilian mothers during the early postpartum period. Data were collected using an interview technique and two instruments: 1) a maternal questionnaire and the 2) Maternal Postpartum Quality of Life tool/Brazilian version. The association between maternal characteristics and quality of life in the postpartum period was investigated with bivariate and multivariable analyses. Results: Mothers who had the best Quality of Life were white, registered students, 30 - 40 years of age, who were married or living with a partner, and without physical complaints; in addition, they had at least an 8th grade education, more than 4 children, and had attended more than 8 prenatal visits with a nurse. The stepwise model indicated that white race $(p<0.05)$ and married or living with a partner $(p<$ 0.05) were the best predictors of Quality of Life in postpartum women. Conclusions and Clinical Implications: Marital status and race conditions may predict quality of life in postpartum Brazilian mothers. In addition, improved knowledge concerning the postpartum, maternal experience may help develop health interventions to enhance the quality of life of this population.
\end{abstract}

\section{Keywords}

Mothers, Postpartum, Quality of Life, Predictors 


\section{Introduction}

The postpartum period can have a significant physical, emotional, and social impact on the quality of life for new mothers due to complications such as postpartum depression [1] [2], urinary incontinence [3] and difficulty in resuming sexual activity [4]. Although often considerably decreased, there is little information regarding the quality of life in postpartum women. Although the importance of postnatal morbidity has recently been recognized [5] [6], information regarding its impact on mother's experiences is limited, and research investigating the quality of life in postpartum women is necessary to improve maternal health.

The term quality of life (QoL) is the result of a historical process whose conceptual beginnings emerged in 384. B.C., when Aristotle referred to the association between happiness and well-being. The concept of QoL was outlined by philosophers, theologians and others, leading to improved conceptualizing of the topic over time [7]. Subsequently, from 1975 until the present, the concept of QoL has been investigated in diverse populations and health conditions and a wide variety of conceptual models exist to define quality of life. Overall, QoL is a multidimensional concept, measuring different aspects of life, including physical well-being as well as psychological and social functioning [8]-[11]. It was not until 1994, after 10 years of analysis, that the World Health Organization Quality of Life group (WHOQOL) released its definition of QoL: “An individual's perception of their position in life in the context of the culture and value systems in which they live and in relation to their goals, expectations, standards and concerns. It is a broad concept, affected in a complex way by the person's physical health, psychological state, level of independence, social relationships, personal beliefs, and their relationship with environmental characteristics" [12]. Eventually QoL was included as a concept in health science research, and presently encompasses the physical, social, and emotional dimensions of wellness, and moves beyond the absence of disease.

Currently, there is a growing interest in transforming QoL into a quantitative measure using an individual's perception to calculate QoL scores [13]-[15]. Pamela Hill et al., (2006) [15] developed the "Maternal Postpartum Quality of Life Tool” (MAPP-QoL), which was the first self-administered instrument for measuring QoL specifically during the early postpartum period. Hill, Aldag, Hekel, Riner, \& Bloomfield, (2006) [15] also demonstrated the reliability and validity of the MAPP-QoL for measuring QoL in postpartum women (Cronbach's alpha coefficients ranged from 0.82 to 0.96 ). Research regarding the MAPP-QoL has been conducted only in the United States in a population with little racial, ethnic, or socioeconomic diversity, suggesting the need for additional testing in more diverse populations [15].

Therefore, the purpose of this study is to explore predictors affecting quality of life in postpartum Brazilian women using the MAPP-QoL. The specific aims are to describe the following: 1) maternal variables and quality of life in Brazilian mothers during the postpartum period, 2) the relationship between maternal variables and quality of life during the postpartum period, and 3) predictors of quality of life among Brazilian postpartum mothers.

\section{Methods}

\subsection{Study Design and Participants}

This study was a cross-sectional survey of QoL in postpartum mothers in the city of Fortaleza in northeast Brazil. Data collection was performed between April and July of 2012. The study was approved by the ethics committee at Federal University of Ceara, Fortaleza, Brazil and all participants provided written informed consent prior to study commencement.

Eligibility criteria included: age $\geq 18$ years (this procedure was used for each woman interviewed could sign his own term of responsibility to participate in the study.), between 7 and 10 days postpartum (recommendation from author of the scale) and without obstetric complications related to the current birth (enable the study of quality of life in women without clinical complications) or any physical or mental constraints (preventing them from understanding the study related interviews and questionnaires). Exclusion criteria included: multiple gestation, obstetric, or neonatal complications during or after childbirth as well as delivering an infant with congenital abnormalities. All eligible patients were contacted by the research team and asked to complete a questionnaire during their follow-up consultation in an Obstetrics \& Gynecology clinic of a public hospital in Fortaleza city, Brazil. Among a population of 4356 women (total demand in 2011) who attended the clinic, a sample of 210 was selected according to the inclusion criteria. The selection of the sample $(n=210)$ was proceeded in a syste- 
matic way and non-probabilistic.

Data collection was conducted through interview technique, and guided by two data collection instruments: 1) the maternal socio-demographic and obstetric questionnaire and the 2) Brazilian version of the MPPQ-QoL. Maternal socio-demographic characteristics including age, marital status, occupation, educational level, monthly income (US \$) of the patient and race were collected from the maternal interviews. Obstetric demographics included parity, number of children, type of delivery method, number of prenatal consultations, type of professional that performed prenatal care, and the type of QoL health education provided in prenatal visits as well as in the hospital prior to discharge.

\subsection{Quality of Life Scores in the Postpartum Period (MAPP-QoL)}

The MAPP-QoL is an index for measure Quality of Life in postpartum period and was developed by Pamela Hill, Aldag, Hekel, Riner, \& Bloomfield (2006) [15] according to the definition, domains, and conceptual model by Ferrans \& Powers (1985) [16] and has been found to be valid and reliable for use in mothers during the early postpartum period following hospital discharge [17]. For this study we used the Brazilian version of the MAPPQoL, which is the result of careful transcultural adaptation and English to Portuguese translation. The final version obtained Cronbach's alpha coefficients of 0.88 . The Brazilian version of the MAPP-QoL contains 39 questions regarding satisfaction and importance of Quality of Life in the postpartum period and used a Likert-type scale (1 - 6) with a score range of 0 - 30 [17]. Scores are calculated by weighting each satisfaction response with its paired importance response. They are calculated by centering the scale on 0 for satisfaction items, multiplying paired satisfaction and importance responses, summing the resultant weighted items, dividing by the number of items answered, and adding 15 to every score to eliminate negative values. (A computer program is available from Ferrans [18].) Thus, the calculation of scores for satisfaction and importance resulted in one score per item; for example, for item 1 ([QOL 1 satisfaction - 3.5]*QOL 1 importance). A description of the steps for calculating the scores can be found on the QoL web site [18].

\subsection{Statistical Analysis}

Data analysis was conducted using the Statistical Package for Social Sciences (SPSS), version 21.0 [19]. Preliminary data analysis began with examination of descriptive statistics (mean, standard deviation, and frequencies) and outliers to clean the data set. Refusals and missing values, which constituted less than $10 \%$ of the data, were replaced using variable means. Some authors have suggested that case mean substitution works reasonably well when less than $30 \%$ of item values on a scale are missing [20].

The $t$-test and One Way ANOVA test were used to perform bivariate analysis to check the association between the independent variables (maternal socio-demographic and obstetric characteristics) and the dependent variables (quality of life during the postpartum period-MAPP-QoL scores). Such associations were considered statistically significant when the p value was $\leq 0.05$ [20]. Stepwise multiple regression analysis was used to assess which predictor variables independently account for variance in MAPPQ-QoL scores, after checking the assumptions.

\section{Results}

\subsection{Descriptive Statistics (Sample Characteristics)}

The frequency distributions for socio-demographics and obstetric characteristics are shown in Table 1. Mothers in this sample $(\mathrm{n}=210)$ tended to be young adults $(65.3 \%)$, married or living with a partner $(79.5 \%)$, have formal (e.g. with full labor rights) or informal employment (e.g. without labor rights) (62.8\%), a high school education (42.9\%), low monthly income (46.7\% received less than US \$678.00/month with an average monthly income of US $\$ 524.90 /$ month) and white (53.8\%).

Distribution of obstetric characteristics indicates the majority of women were multiparous (57.1\%), with 2 or 3 children (45.7\%). Type of delivery had a similar frequency ( $52.4 \%$ caesarian section and $47.6 \%$ vaginal). Only $72.4 \%$ of women reported they did not experience physical complaints during the postpartum period. Over half of all mothers (59.0\%) attended between 6 and 8 prenatal visits (average was 3 visits) and 54\% of these visits were performed by a physician. More than half of women did not receive health education regarding QoL during the postpartum period; however, 67.6\% received health education regarding QoL in the hospital immediately 
Table 1. Sample characteristics.

\begin{tabular}{|c|c|c|c|c|}
\hline \multirow{2}{*}{ Characteristics } & \multirow{2}{*}{ N (\%) } & \multirow{2}{*}{$\begin{array}{c}\text { Mean } \\
\left( \pm \mathrm{SD}^{*}\right)\end{array}$} & \multicolumn{2}{|c|}{ Value } \\
\hline & & & Min & Max \\
\hline \multicolumn{5}{|l|}{ Demographics } \\
\hline \multicolumn{5}{|l|}{ Age (years) } \\
\hline$\leq 20 \mathrm{y}$ & $48(22.9)$ & \multirow{4}{*}{$\begin{array}{c}26.87 \\
( \pm 7.28)\end{array}$} & \multirow{4}{*}{18} & \multirow{4}{*}{45} \\
\hline $21-30 y$ & 89 (42.4) & & & \\
\hline $31-40 y$ & $61(29.0)$ & & & \\
\hline$>40 \mathrm{y}$ & $12(5.7)$ & & & \\
\hline \multicolumn{5}{|l|}{ Marital status } \\
\hline Married/with partner & 167 (79.5) & - & & \\
\hline Single & $43(20.5)$ & - & & \\
\hline \multicolumn{5}{|l|}{ Occupation } \\
\hline Unemployed & $19(9.0)$ & - & & \\
\hline Housewife & $49(23.3)$ & - & & \\
\hline Student & $10(4.8)$ & - & & \\
\hline Formal employment & $66(31.4)$ & - & & \\
\hline Informal employment & $66(31.4)$ & - & & \\
\hline \multicolumn{5}{|l|}{ Education } \\
\hline 8th grade or less & $74(35.3)$ & - & & \\
\hline Grades 9 - 11 & $31(14.8)$ & - & & \\
\hline High school & 90 (42.9) & - & & \\
\hline Some college & $7(3.3)$ & - & & \\
\hline Bachelor’s degree & $8(3.8)$ & - & & \\
\hline \multicolumn{5}{|c|}{ Monthly income (U\$) of the patient } \\
\hline$<678.00$ & $98(46.7)$ & & & \\
\hline $678.00-1017.00$ & $89(42.4)$ & $\begin{array}{c}524.90 \\
( \pm 419.26)\end{array}$ & 0 & 3.333 \\
\hline$>1017.00$ & $23(11.0)$ & & & \\
\hline \multicolumn{5}{|l|}{ Race } \\
\hline White & $186(88.6)$ & - & & \\
\hline Black & $20(9.5)$ & - & & \\
\hline Asian & $4(1.9)$ & - & & \\
\hline \multicolumn{5}{|l|}{ Obstetrics } \\
\hline \multicolumn{5}{|l|}{ Parity } \\
\hline Primiparous & $90(42.8)$ & \multirow{2}{*}{$1.97( \pm 1.46)$} & \multirow[t]{2}{*}{0} & \multirow[t]{2}{*}{11} \\
\hline Multiparous & $120(57.1)$ & & & \\
\hline \multicolumn{5}{|l|}{ Number of children } \\
\hline 1 & $93(44.3)$ & & & \\
\hline $2-3$ & $96(45.7)$ & $\begin{array}{c}1.99 \\
( \pm 1.30)\end{array}$ & 1 & 11 \\
\hline$\geq 4$ & $21(10.0)$ & & & \\
\hline \multicolumn{5}{|l|}{ Type of delivery (last) } \\
\hline Abdominal & $110(52.4)$ & - & & \\
\hline Vaginal & $100(47.6)$ & - & & \\
\hline
\end{tabular}




\section{Continued}

\begin{tabular}{|c|c|c|c|c|}
\hline \multicolumn{5}{|l|}{ Physical complaints } \\
\hline No & $152(72.4)$ & - & & \\
\hline Yes & $58(27.6)$ & - & & \\
\hline \multicolumn{5}{|l|}{ Number prenatal visits } \\
\hline None & $3(1.4)$ & \multirow{4}{*}{$\begin{array}{c}2.85 \\
( \pm 0.65)\end{array}$} & & \multirow{4}{*}{14} \\
\hline$<6$ & $54(25.7)$ & & & \\
\hline $6-8$ & $124(59.0)$ & & 1 & \\
\hline$>8$ & $29(13.8)$ & & & \\
\hline \multicolumn{5}{|c|}{ Professional performing prenatal care } \\
\hline Nurse & $30(14.3)$ & - & & \\
\hline Physician & $114(54.3)$ & - & & \\
\hline Nurse + physician & $63(30.0)$ & - & & \\
\hline None & $3(1.4)$ & & & \\
\hline \multicolumn{5}{|c|}{ Health education regarding QoL ${ }^{* *}$ during prenatal visits } \\
\hline No & $142(67.6)$ & - & & \\
\hline Yes & $68(32.4)$ & - & & \\
\hline \multicolumn{5}{|c|}{ Health education regarding QoL in hospital prior to discharge } \\
\hline Yes & $142(67.6)$ & - & & \\
\hline No & $68(32.4)$ & - & & \\
\hline
\end{tabular}

*SD = Standard deviation; ${ }^{* *}$ QoL = Quality of life.

prior to discharge.

\subsection{Bivariate Analysis (Factors Associated with QoL in Postpartum Period)}

QoL scores reported among Brazilian mothers during the postpartum period and their correlation with sociodemographics and obstetric characteristics are listed in Table 2.

Mean scores for the MAPP-QoL was 15.24 ( \pm 0.08 ), with a small variance of 14.85 to 15.38 . The range possible for this scale is 0 to 30. Better QoL score is related to the best conditions of quality of life [15]. A small standard deviation (SD) was found indicating the sample adequately represented the population [20].

The highest QoL scores were in white women 30 - 40 years of age, who were married, or living with a partner, working as a student, and achieved a high school or 8th grade education. QoL was similar for all monthly income groups, parity, type of delivery method, and whether or not they received QoL health education prior to hospital discharge. The mean QoL score was significantly higher for mothers with more than 4 children, without physical complaints, who attended more than 8 prenatal visits performed by a nurse and who did not receive health education about QoL during prenatal care.

Marital status $(p=0.01)$, educational level $(p=0.01)$ and race $(p=0.04)$ were significantly correlated with QoL and were therefore included in the multiple regression analyses to evaluate for prediction.

\subsection{Multivariate Analysis (Predictors of QoL in Postpartum Women)}

Stepwise multiple regression analysis was utilized to assess the strength of the association between the predictor variables and the independent MAPP-QoL scores. Table 3 shows the results of stepwise multiple regression analysis with predictor variables and QoL.

The first predictor variable included in the stepwise regression was marital status, which had the highest bivariate correlation with a dependent variable (DV): QoL. The predictor variable selected in the second step was race followed by educational level. Due to the combination of variables, assumptions for multicollinearity were examined. In the regression equation, the tolerance was 1.00 and the VIF in the final model was 1.00 , so the assumptions for multicollinearity were not violated. The stepwise model included as the best predictor in race was 
Table 2. Score distribution and differences in MAPP-QoL according demographics and obstetrics characteristics from Brazilians mothers.

\begin{tabular}{|c|c|c|c|}
\hline \multirow{2}{*}{$\begin{array}{l}\text { Characteristics } \\
\text { Demographics }\end{array}$} & \multirow[b]{2}{*}{ Mean $( \pm$ SD) } & \multicolumn{2}{|c|}{ MAPP-QoL scores } \\
\hline & & T-score ${ }^{a}$ or F-ratio ${ }^{b}$ & p value \\
\hline Age & & $2.16^{\mathrm{b}}$ & \\
\hline$\leq 20 \mathrm{y}$ & $15.23( \pm 0.09)$ & & \\
\hline $21-30 y$ & $15.23( \pm 0.09)$ & & \\
\hline $31-40 y$ & $15.26( \pm 0.07)$ & & 0.0 \\
\hline$>40 \mathrm{y}$ & $15.23( \pm 0.10)$ & & \\
\hline Marital status & & $2.50^{\mathrm{a}}$ & \\
\hline Married/with partner & $15.25( \pm 0.08)$ & & $0.01^{*}$ \\
\hline Single & $15.21( \pm 0.09)$ & & \\
\hline Occupation & & $0.48^{\mathrm{b}}$ & \\
\hline Unemployment & $15.24( \pm 0.08)$ & & \\
\hline Housewife & $15.22( \pm 0.10)$ & & \\
\hline Student & $15.26( \pm 0.07)$ & & 0.74 \\
\hline Formal employment & $15.24( \pm 0.08)$ & & \\
\hline Informal employment & $15.24( \pm 0.08)$ & & \\
\hline Education & & $4.62^{\mathrm{b}}$ & \\
\hline 8th grade or less & $15.25( \pm 0.07)$ & & \\
\hline Grades 9 - 11 & $15.21( \pm 0.09)$ & & \\
\hline High school & $15.25( \pm 0.08)$ & & $0.01^{*}$ \\
\hline Some college & $15.14( \pm 0.15)$ & & \\
\hline Bachelor's degree & $15.18( \pm 0.08)$ & & \\
\hline Monthly income of the patient & & $0.06^{\mathrm{b}}$ & \\
\hline$<$ US \$ 678.00 & $15.24( \pm 0.09)$ & & \\
\hline US $\$ 678.00-1017.00$ & $15.24( \pm 0.08)$ & & 0.83 \\
\hline >US \$ 1017.00 & $15.24( \pm 0.10)$ & & \\
\hline Race & & $2.80^{\mathrm{b}}$ & \\
\hline White & $15.26( \pm 0.07)$ & & \\
\hline Black & $15.22( \pm 0.09)$ & & $0.04^{*}$ \\
\hline Asian & $15.24( \pm 0.05)$ & & \\
\hline \multicolumn{4}{|l|}{ Obstetrics } \\
\hline Parity & & $0.04^{\mathrm{b}}$ & \\
\hline Primiparous & $15.24( \pm 0.01)$ & & 009 \\
\hline Multiparous & $15.24( \pm 0.02)$ & & 0.05 \\
\hline Number of children & & $0.16^{\mathrm{b}}$ & \\
\hline 1 & $15.24( \pm 0.07)$ & & \\
\hline $2-3$ & $15.23( \pm 0.09)$ & & 0.12 \\
\hline$\geq 4$ & $15.25( \pm 0.09)$ & & \\
\hline
\end{tabular}




\section{Continued}

Type of delivery (last)

Caesarian section

Vaginal

Physical Complains

No

Yes

Number prenatal visits

None

$<6$

$6-8$

$>8$

Professionally performed prenatal care

Nurse

Physician

Nurse + physician

None

Health education regarding QoL in prenatal visits

No

Yes

Health education regarding QoL in hospital (immediately prior to discharged)

Yes

No $0.21^{\mathrm{a}}$

$15.24( \pm 0.08)$

$15.24( \pm 0.09)$

$15.24( \pm 0.09)$

$15.23( \pm 0.07)$

0.63

$1.14^{\mathrm{b}}$

$15.16( \pm 0.04)$

$15.24( \pm 0.01)$

$15.23( \pm 0.01)$

$15.25( \pm 0.00)$

$1.17^{\mathrm{b}}$

$15.25( \pm 0.06)$

$15.24( \pm 0.08)$

$15.23( \pm 0.10)$

$15.16( \pm 0.07)$

$15.24( \pm 0.08)$

$15.23( \pm 0.09)$

$0.62^{\mathrm{b}}$

$15.24( \pm 0.09)$

$15.24( \pm 0.08)$

$-0.47^{\mathrm{a}}$

0.32 aby T-test, b: by ANOVA; Overall MAPP-QoL total score $(\mathrm{n}=210)$, Mean $=15.24( \pm 0.08)$, Range actual $(14.85-15.38)$, Range possible $\left(0\right.$ - 30); ${ }^{*} \mathrm{p}$ $<0.05$, correlation significant; Note: There are illiterates in our sample, But the illiterates were allocated in the following category of education: "8th grade or less".

Table 3. Stepwise multiple regression between predictors and QOL in postpartum (MAPP-QoL).

\begin{tabular}{ccccccccccc}
\hline Predictor variable & \multirow{2}{*}{ B } & SE & $\beta$ & R-Square & $\begin{array}{c}\text { Adjusted } \\
\text { R-Square }\end{array}$ & \multicolumn{2}{c}{ 95\% CI for B } \\
\hline Race (White) & & & & & & & & Lower & Upper & P \\
Marital status (Married/live with partner) & 0.038 & 0.015 & 0.171 & 0.69 & 0.60 & 0.009 & 0.067 & $0.011^{*}$ \\
\hline
\end{tabular}

Overall $\mathrm{R}^{2}=0.69$, Adjusted $\mathrm{R}^{2}=0.60, \mathrm{~F}(2,14)=7.63, \mathrm{p}=0.001 ;{ }^{*} \mathrm{p}<0.05$, correlation significant, B—partial regression coefficient; SE—standard error; $\beta$-standardized regression coefficient; $\mathrm{CI}$-confidence interval; $\mathrm{R}$-variance.

white $(\mathrm{p}<0.05)$ and in marital status was married/live with partner $(\mathrm{p}<0.05)$. Black race $(\mathrm{p}=0.78)$ and all educational levels $(\mathrm{p}>0.05)$ were excluded from the stepwise model.

We obtained an $\mathrm{R}^{2}$ of 0.39 (adjusted $\mathrm{R}^{2}=0.35$ ) for white race; thus, $35 \%$ of the variance in QoL in postpartum was explained by white race alone. When marital status (married/living with partner) was added to the equation of stepwise regression, $\mathrm{R}^{2}$ increased to 0.69 (adjusted $\mathrm{R}^{2}=0.60$ ); therefore, $60 \%$ of the variance in QoL in postpartum women was explained by white race and marital status (married/living with partner).

Regarding individual predictors, the regression coefficient B for all predictors different from zero contributes significantly to the prediction of QoL during the postpartum period [20]. The Confidence Interval (95\%) did not contain the value 1 , and therefore the relationship between the predictors (race and marital status) and DV (QoL in postpartum) is generalizable. 


\section{Discussion}

This study examined the overall perceived QoL during the early postpartum period in Brazilian mothers of term infants. Results indicate that marital status and race may predict the quality of life during the postpartum period; in particular, women who were white and either married or living with a partner had higher QoL scores.

\subsection{Socio-Demographics Characteristics}

Researchers have long known that social conditions, economic status, and health concerns influence the health and well-being of individuals [10] [17]. Findings from this study highlight the importance of continued examination of social support in the postpartum period as well as differences and similarities among women from various racial/ethnic backgrounds [21]. Postpartum Brazilian women who were either married or living with partner were more satisfied with their lives than those who were single, likely due to the fact that social support is an essential component for the postpartum woman's physical and emotional well-being [21]. Previous studies have reported higher QoL scores in mothers with high levels of relationship as well as social support from partners and families [17]. In fact, poor social support has been found to strongly predict postpartum depression [22] [23] and dissatisfaction with social support may increase the risk for clinical and subclinical depression during the postpartum period [24]. Our findings suggest that the health care provider plays a key role in identifying the expectations and needs of new mothers as well as developing strategies to achieve such support, which may decrease the risk of postpartum depression.

Maternal characteristics such as nonwhite race and lower socioeconomic status are risk factors for decreased maternal QoL during the postpartum period [22]. Although the majority of women in this research were of low socioeconomic status, maternal race had a greater contribution to decreased well-being in the postpartum period. It is unclear why race is more important than socioeconomic status regarding postpartum QoL; thus, future studies are necessary to clarify the relationship between racial vulnerability and maternal QoL during the postpartum period.

\subsection{Obstetrics Characteristics}

Although the correlation between the obstetric characteristics (e.g. parity, child number, route of last delivery and physical complaints) and QoL scores in postpartum women were not significant, the difference between groups for each variable was distinct and may be representative of the health and well-being of new mothers. For example, having more than one child was associated with a higher QoL in postpartum mothers, a finding supported by previous research [25]. This may be because maternal memory and responsiveness increase with each child [26], explaining why women with more maternal experience adapt more naturally to motherhood following the birth of a second child. Therefore, primiparous women may represent a vulnerable group that requiring increased attention from health professionals and researchers.

In our study, an association between type of delivery and QoL among Brazilian women was not found. Hill and Aldag (2007) [17] reported that women who delivered via cesarean section had lower QoL scores. Torkan, Parsay, Lamyian, Kazemnejad, \& Montazeri (2009) [27] reported that vaginal delivery improved physical health related quality of life while caesarean section improved mental health related quality of life, and thus the total impact on quality of life was equivalent. Thus, it is not clear the advantage of either method of delivery on QoL, suggesting additional research is needed regarding this association [27].

Timely educational interventions including breastfeeding as well as anticipatory guidance for infant and maternal health may contribute to improved levels of health, and consequently to greater QoL following birth. The relationship between QoL scores and obstetrical factors that may affect women in the post-partum period include frequency of prenatal visits and education about how to improve their QoL following childbirth. Women with the most prenatal visits had the highest QoL, which is supported by Akýn, Ege, Koçoðlu, Demirören, \& Yýlmaz (2009) [28], who found women with more than three prenatal visits had higher QoL scores than women with fewer visits.

The roles of some obstetrics characteristics like prior method of delivery and health education during prenatal visits had less impact on postpartum QoL than the experience of having several children. This indicates that multiple children provides mothers with the experience they need to adjust to the demands of motherhood. In addition, women with adequate social support have an increased chance of experiencing a healthy postpartum 
period. In contrast, conditions such as primiparity and poor social support are risks for poor QoL during the postpartum period, and women vulnerable to these factors deserve special attention from health professionals.

\subsection{Limitations and Recommendations for Future Studies}

Several limitations existed in this study. First, the sample size was small and utilized only one site for data collection. Generalization to sociodemographically dissimilar samples may be problematic and therefore a larger and more diverse sample of mothers is required. Second, a re-test was not performed, limiting the analysis regarding stability of the measuring instrument. Future longitudinal studies are needed to clarify the stability of quality of life at different times of the postpartum period.

Postpartum mothers should be informed that their personal health satisfaction and overall QoL will likely improve with time [17]. This point should be emphasized when health care providers evaluate maternal needs and when researchers develop health promotion interventions for each stage of the postpartum period.

\section{Conclusion and Clinical Implications}

Health care providers should be sensitive to predictors of women's quality of life in the postpartum period, including race and marital status, as well as conditions associated with maternal vulnerability such as extreme age, lack of social support, nonwhite race, unemployment, low level of education, low socioeconomic status, birth of only one child, presence of physical complaints, few prenatal visits, and lack of education regarding QoL in the postpartum period. In addition, improved knowledge concerning the postpartum and maternal experience may assist in the development of health interventions to enhance the quality of life in this population.

\section{Conflict of Interest}

No conflict declared.

\section{Acknowledgements}

This research was supported by Conselho Nacional de Desenvolvimento Científico e Tecnológico (CNPq) of Brazil, process number 245286/2012-8 during one Doctoral Exchange in the College of Nursing/University of Florida in 2014.

\section{References}

[1] Dennis, C.L. (2005) Psychosocial and Psychological Interventions for Prevention of Postnatal Depression: Systematic Review. BMJ, 331, 1-8. http://dx.doi.org/10.1136/bmj.331.7507.15

[2] Halligan, S.L., Murray, L., Martins, C. and Cooper, P.J. (2007) Maternal Depression and Psychiatric Outcomes in Adolescent Offspring: A 13-Year Longitudinal Study. Journal of Affective Disorders, 97, 145-154. http://dx.doi.org/10.1016/j.jad.2006.06.010

[3] Groutz, A., Rimon, E., Peled, S., Gold, R., Pauzner, D., Lessing, J. B. and Gordon, D. (2004) Cesarean Section: Does It Really Prevent the Development of Postpartum Stress Urinary Incontinence? A Prospective Study of 363 Women One Year after Their First Delivery. Neurourology and Urodynamics, 23, 2-6. http://dx.doi.org/10.1002/nau.10166

[4] Brubaker, L., Handa, V.L., Bradley, C.S., Connolly, A., Moalli, P., Brown, M.B. and Weber, A. (2008) Sexual Function 6 Months after First Delivery. Obstetrics and Gynecology, 111, 1040-1044. http://dx.doi.org/10.1097/AOG.0b013e318169cdee

[5] Souza, J.P., Cecatti, J.G., Parpinelli, M.A., de Sousa, M.H. and Serruya, S.J. (2006) Systematic Review of Near Miss Maternal Morbidity. Cadernos de Saúde Pública, 22, 255-264. http://dx.doi.org/10.1590/S0102-311X2006000200003

[6] Mogos, M.F., August, E.M., Salinas-Miranda, A.A., Sultan, D.H. and Salihu, H.M. (2013) A Systematic Review of Quality of Life Measures in Pregnant and Postpartum Mothers. Applied Research in Quality of Life, 8, 219-250. http://dx.doi.org/10.1007/s11482-012-9188-4

[7] Fayers, P.M. and Machin, D. (2007) Quality of Life: The Assessment, Analysis and Interpretation of Patient-Reported Outcomes. John Wiley \& Sons, Chichester. http://dx.doi.org/10.1002/9780470024522

[8] Steger, M.F., Frazier, P., Oishi, S. and Kaler, M. (2006) The Meaning in Life Questionnaire: Assessing the Presence of and Search for Meaning in Life. Journal of Counseling Psychology, 53, 80-93. http://dx.doi.org/10.1037/0022-0167.53.1.80 
[9] Symon, A., MacDonald, A. and Ruta, D. (2002) Postnatal Quality of Life Assessment: Introducing the Mother Generated Index. Birth, 29, 40-46. http://dx.doi.org/10.1046/j.1523-536X.2002.00154.X

[10] Fryback, D.G. (2010) Measuring Health-Related Quality of Life. Workshop on Advancing Social Science Theory: The Importance of Common Metrics. The National Academies, Division of Behavioral and Social Sciences and Education, Washington DC.

[11] O’Connor, R. (2004) Measuring Quality of Life in Health. Churchill Livingston, Edinburgh.

[12] Kuyken, W., Orley, J., Power, M., Herrman, H., Schofield, H. and Murphy, B. (1995) The World Health Organization Quality of Life Assessment (WHOQOL): Position Paper from the World Health Organization. Social Science \& Medicine, 41, 1403-1409. http://dx.doi.org/10.1016/0277-9536(95)00112-K

[13] Bowling, A. (1995) What Things Are Important in People's Lives? A Survey of the Public's Judgements to Inform Scales of Health Related Quality of Life. Social Science \& Medicine, 41, 1447-1462. http://dx.doi.org/10.1016/0277-9536(95)00113-L

[14] Kleinpell, R.M. (1997) Whose Outcomes. Patients, Providers, or Payers? The Nursing Clinics of North America, 32, 513-520.

[15] Hill, P.D., Aldag, J.C., Hekel, B., Riner, G. and Bloomfield, P. (2006) Maternal Postpartum Quality of Life Questionnaire. Journal of Nursing Measurement, 14, 205-220. http://dx.doi.org/10.1891/jnm-v14i3a005

[16] Ferrans, C.E. and Powers, M.J. (1985) Quality of Life Index: Development and Psychometric Properties. Advances in Nursing Science, 8, 15-24. http://dx.doi.org/10.1097/00012272-198510000-00005

[17] Hill, P.D. and Aldag, J.C. (2007) Maternal Perceived Quality of Life Following Childbirth. Journal of Obstetric, Gynecologic, \& Neonatal Nursing, 36, 328-334. http://dx.doi.org/10.1111/j.1552-6909.2007.00164.x

[18] Ferrans, C. and Powers, M. (1992) Psychometric Assessment of the Quality of Life Index. Research in Nursing \& Health, 15, 29-38. http://dx.doi.org/10.1002/nur.4770150106

[19] IBM Corp. (2012) IBM SPSS Statistics for Windows, Version 21.0. IBM Corp., Armonk.

[20] Polit, D.F. and Lake, E. (2010) Statistics and Data Analysis for Nursing Research. Pearson, New York.

[21] Negron, R., Martin, A., Almog, M., Balbierz, A. and Howell, E.A. (2012) Social Support during the Postpartum Period: Mothers' Views on Needs, Expectations, and Mobilization of Support. Maternal and Child Health Journal, 17, 616623. http://dx.doi.org/10.1007/s10995-012-1037-4

[22] Howell, E.A., Mora, P. and Leventhal, H. (2006) Correlates of Early Postpartum Depressive Symptoms. Maternal and Child Health Journal, 10, 149-157. http://dx.doi.org/10.1007/s10995-005-0048-9

[23] Logsdon, M.C. and Usui, W. (2001) Psychosocial Predictors of Postpartum Depression in Diverse Groups of Women. Western Journal of Nursing Research, 23, 563-574. http://dx.doi.org/10.1177/01939450122045384

[24] Beck, C.T., Records, K. and Rice, M. (2006) Further Development of the Postpartum Depression Predictors Inventory Revised. Journal of Obstetric, Gynecologic, \& Neonatal Nursing, 35, 735-745. http://dx.doi.org/10.1111/j.1552-6909.2006.00094.x

[25] O’Hara, M.W., Zekoski, E.M., Philipps, L.H. and Wright, E.J. (1990) Controlled Prospective Study of Postpartum Mood Disorders: Comparison of Childbearing and Nonchildbearing Women. Journal of Abnormal Psychology, 99, 315. http://dx.doi.org/10.1037/0021-843X.99.1.3

[26] Pawluski, J.L. and Galea, L.A.M. (2007) Reproductive Experience Alters Hippocampal Neurogenesis during the Postpartum Period in the Dam. Neuroscience, 149, 53-67. http://dx.doi.org/10.1016/j.neuroscience.2007.07.031

[27] Torkan, B., Parsay, S., Lamyian, M., Kazemnejad, A. and Montazeri, A. (2009) Postnatal Quality of Life in Women after Normal Vaginal Delivery and Caesarean Section. BMC Pregnancy and Childbirth, 9, 4. http://dx.doi.org/10.1186/1471-2393-9-4

[28] Akýn, B., Ege, E., Koçoðlu, D., Demirören, N. and Yýlmaz, S. (2009) Quality of Life and Related Factors in Women, Aged 15-49 in the 12-Month Post-Partum Period in Turkey. Journal of Obstetrics and Gynaecology Research, 35, 86-93. http://dx.doi.org/10.1111/j.1447-0756.2008.00870.x 